\title{
Land use/cover change detection based on remote sensing data (A case study; Neka Basin)
}

\author{
K. Solaimani ${ }^{1}$, M. Arekhi' ${ }^{2}$ R. Tamartash ${ }^{3}$, M. Miryaghobzadeh ${ }^{4}$ \\ ${ }^{1}$ GIS \& RS Centre, University of Agriculture and Natural Resources, P.o.Box 737 Sari-Iran \\ solaimani2001@yahoo.co.uk, Tel: +989111521858 \\ ${ }^{2}$ M.Sc student of Range Management, University of Agriculture and Natural Resources, P.O. \\ Box 737 Sari-Iran \\ ${ }^{3}$ Instructor of University of Agriculture and Natural Resources of Sari, Iran \\ ${ }^{4} \mathrm{Ph}$.D. Student in Watershed Management, University of Agriculture and Natural Resources \\ of Sari, Iran \\ ABSTRACT
}

\begin{abstract}
Several regions around the world are currently under rapid, wide-ranging changes of land cover. Satellite remote sensing techniques have proven to be cost efficient in extensive land cover changes. This study illustrates the effect of land use/cover change in Neka river of Iran using topographic maps and multi-temporal remotely sensed data from 1975 to 2001 . The Maximum likelihood supervised classification technique was used to extract information from satellite data, and post-classification change detection method was employed to detect land use/cover change. Post-classification change detection technique was used to produce an image through cross-tabulation. Changes among different land use/cover classes were assessed. The overall accuracy of land cover change maps, generated from Landsat data 1975 and 2001, ranged from $99.44 \%$ and $97.08 \%$ with Kappa statistics of $85 \%$ and $83 \%$, respectively. The analysis indicated that the urban and agricultural land expansion of Neka river was increased resulted in the considerable reduction of forest area. The maps showed that between 1987 and 2001 the agricultural land and built-up areas increased approximately $59.86 \mathrm{~km}^{2}(9.16 \%)$ and $7.35(1.13 \%)$, respectively. While forest decreased $67.91 \mathrm{~km}^{2}(10.29 \%)$. The study quantified the patterns of land use/cover change for the last 13 years for Neka river that forms valuable resources for urban planners and decision makers to devise sustainable land use and environmental planning.
\end{abstract}

Keywords: Land Use/Cover , remote sensing, Neka river,-post classification, change detection

\section{INTRODUCTION}

Recently, remote sensing with multi-temporal high resolution satellite data has become a strong tool for monitoring aspects such as vegetation cover, soil degradation, urban expansion and more generally for most types of land-cover/land-use (LC/LU) changes. In contrast to ground-based terrestrial data acquisition, valuable knowledge can be gained in a relatively short time and very cost-effective way. LC/LU classification on the basis of satellite images with appropriate specifications serves as an essential database for planning and making decisions at different administrative levels. The integration of such remote sensing data into a GIS offers a wide variety of new perspectives and possibilities for the analysis, evaluation and interpretation of such data, in combination with auxiliary digital information such as digitised maps (Ozel et al., 1999).Now a days there are a wide variety of methods and transformative techniques available for classifying images according to spectral properties at the pixel level as well as spatial context and texture (Adams et al., 1995; Hill, 1999; Lu, Mausel, Batistella, and Moran, 2004; Lu, Moran, and Batistella, 2003). In order to facilitate between-image comparison, methods have been developed for pre-processing of images that correct for differences in solar angle, atmospheric conditions, and sensor variation (Green, Schweik, and Hanson, 2002; Lu, Mausel, Brondizio, and Moran, 2002). Techniques of automated or semi-automated image interpretation have allowed assessments of land use and land cover changes over large areas to a relative low cost (Asner et al., 2005). LU and LC are not identical. A knowledge of LC does not necessarily define LU. The LU function of an LC type needs to be known in order to understand changes in LC (Lambin and Geist, 2001). There are many definitions of LU (Jansen, 2006) and LC. For this paper, LC is defined as "the observed (bio) physical cover on the earth's 
surface" (Di Gregorio and Jansen, 2000); while LU refers to the manner in which people use these biophysical assets (Cihlar and Jansen, 2001). Geographic Information Systems (GIS) and remote sensing (RS) are powerful and cost-effective tools for assessing the spatial and temporal dynamics of LULC (Hathout, 2002; Herold, et al., 2003; Lambin, Geist, and Lepers, 2003; Serrea et al., 2008). Remote sensing data provide valuable multi-temporal data on the processes and patterns of LULC change, and GIS is useful for mapping and analyzing these patterns (Zhang, et al., 2002). In addition, retrospective and consistent synoptic coverage from satellites is particularly useful in areas where changes have been rapid (Blodget, Taylor, and Roark, 1991). Furthermore, since digital archives of remotely sensed data provide the opportunity to study historical LULC changes, the geographic pattern of such changes in relation to other environmental and human factors can be evaluated. As a result of the population explosion in recent years, areas used for settlements have expanded in extreme proportions. Such expansions have included both planned urbanization and, unfortunately, illegal housing. The obvious fact is that this kind of urbanization, legal or illegal, is consuming vast areas of agriculture land and other green areas which will lead to many harmful consequences for future generations (Maktav and Erberk 2005). Land use/cover change analysis is an important tool to assess global change at various spatial-temporal scales (Lambin 1997). In addition, it reflects the dimension of human activities on a given environment (Lopez et al. 2001). Change detection of land use and land cover is one of the essential practices in many interrelated disciplinary areas, such as soil erosion, deforestation, landscape conservation and ecosystem restoration. Careful monitoring and measurement at different temporal and spatial scales would reveal a fluctuating landscape, punctuated by changes in movement of people, perturbation from environmental disasters, and shifts in activities. Land cover characterization and change detection analysis based on remote sensing are able to provide planners with sufficient background information for model parameterization (Helmschrot and Flugel 2002). With such a need, advanced and improved remote sensing data analysis and land cover classification techniques are anticipated (Foody 2002; Pal and Mather 2003; Steele 2000). Satellite remote sensing has been widely applied and recognized as a powerful and an effective tool for detecting land use and land cover changes (Ehlers et al. 1990; Harris and Ventura 1995; Irish 1990; Treitz et al. 1992; Welch et al. 1988; Westmoreland and Stow 1992). Therefore, determining the trend and the rate of land cover conversion are necessary for the development planner in order to establish rational land use policy. For this purpose, the temporal dynamics of remote sensing data can play an important role in monitoring and analyzing land cover changes. Accurate and up-to-date land cover change information is necessary to understanding and assessing the environmental consequences of such changes (Giri, Zhu, and Reed, 2005). While remote sensing has the capability of capturing such changes, extracting the change information from satellite data requires effective and automated change detection techniques (Roy, Lewis, and Justice, 2002). Digital change detection is the process of determining and/or describing changes in land-cover and landuse properties based on co-registered multi-temporal remote sensing data. The basic premise in using remote sensing data for change detection is that the process can identify change between two or more dates that is uncharacteristic of normal variation. Numerous researchers have addressed the problem of accurately monitoring land-cover and land-use change in a wide variety of environments (Chan, Chan, and Yeh, 2001; Muchoney and Haack, 1994; Singh, 1989). Many studies have discussed land cover and land use changes in arid, semi-arid and agricultural productive land. Palmer and Van Rooyen (1998) used Landsat TM data to explore the impacts of land management policies on vegetation structure in two study areas in southern Kalahari desert in South Africa in the period 1989-1994. Ram and Kolarkar (1993) studied land use changes in arid areas in India by visual comparison of satellite imagery, maps and aerial photographs.

Post-classification comparisons of derived thematic maps go beyond simple change detection and attempt to quantify the different types of change. The degree of success depends upon the reliability of the maps made by image classification (Foody and Boyd, 1999; Khorram et al., 1999). This paper describes the results of land use/cover classification in Neka river of Iran derived from topographic maps and multitemporal remotely sensed data. Specifically, the aim of this paper is to dynamically map and investigation the land use/ cover change and to analyze the changes with respect to the baseline of 1975. Since there is a lack of reliable data such as official land use maps and restricted access to aerial 
photographs, it was appropriate to use satellite data for the assessment of land cover change.

Study Area: The study area of Neka watershed is geographically located in northern flank of Alborz ranges of Iran and drainages to the Caspian Sea (Fig. 1). Its area was calculated $654.85 \mathrm{~km}^{2}$ using digital planimeter on 1:50,000 topographic map of the Iranian Geographical Organization. The land cover of this area is mostly as forest covers which is belonged to the southern Caspian ecosystem and geologically based on Jurassic formation. The climatic characteristics is classified as moderate conditions with an annual average temperature of 17 degree and the mean annual rainfall in this area is estimated about $548 \mathrm{~mm}$. with a record of over $50 \%$ in the wet seasons of autumn and winter. In geomorphologic view, this area is nearly flat to very gentle slope with elevation of $340 \mathrm{~m}$. The soil type is classified as silt loam, loam, silt clay loam, loamy sands, and sands. In the study, a variety of data, including satellite images, standard 1:50,000 scale topographic maps and various thematic maps obtained from the various sources, have been used as data sources together with ground truth which have helped together to gained the purposed results.

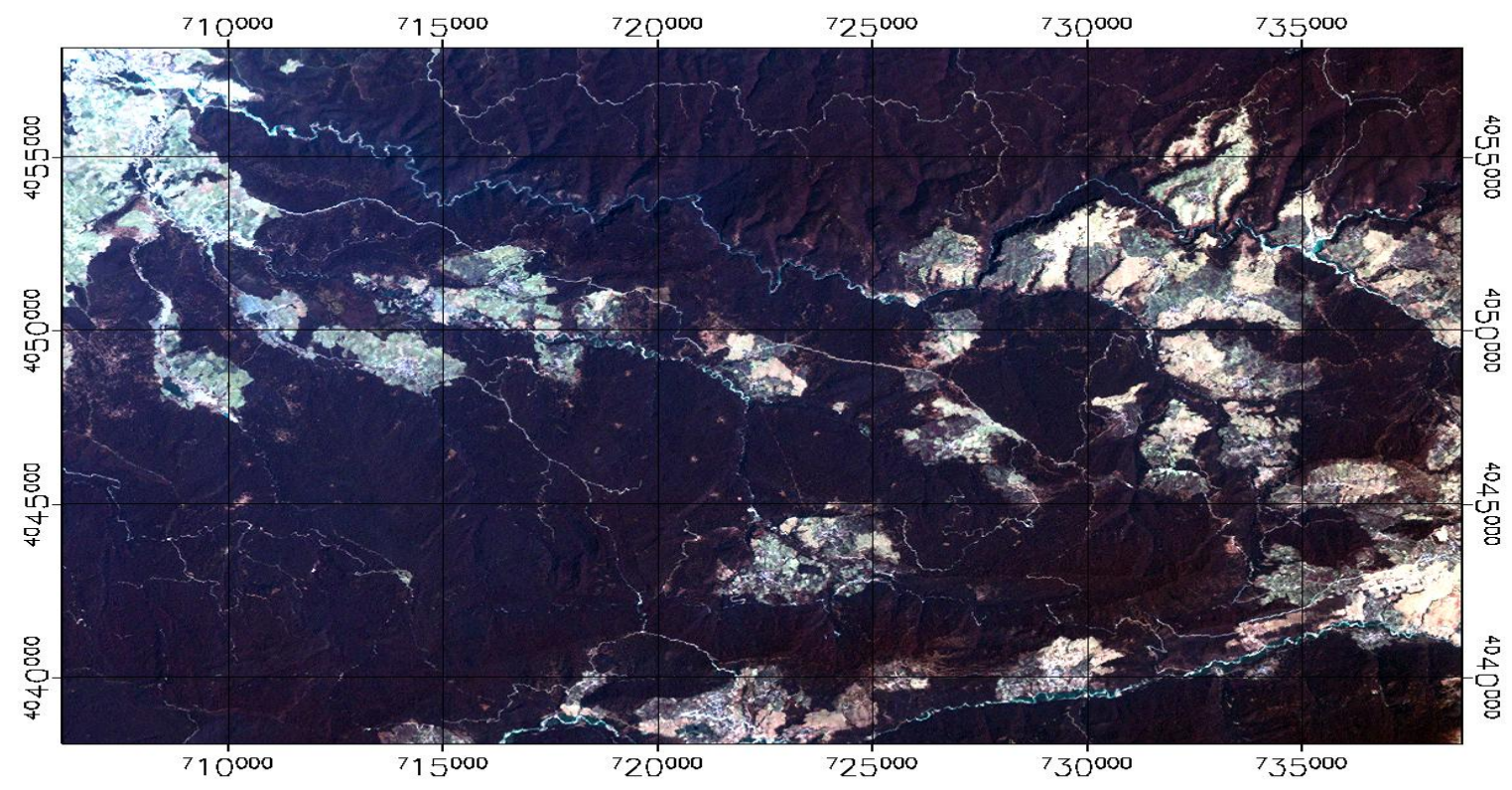

\section{MATERIALS AND METHODS}

Pre-processing: In pre-processing the following major steps were applied on images which are included; georeferencing, radiometric calibration, atmospheric and radiometric rectification. In classification process, the Landsat TM data of 1975 and 2001 were classified into three spectral classes using the conventional supervised Maximum Likelihood Classification Alogorithm. The geometric rectification is critical to produce a spatially corrected map of land use/cover changes through a period. The geometric correction was applied using topographic maps at the scale of 1:50,000 which completed with a numbers of control points extracted from GPS. The nearest neighbor resampling method was used to avoid altering the original pixel values of the image data. Thus, the image of 2001 was geometrically corrected using 39 control points. The root mean square error (RMSE) was estimated about 0.11 pixels. The geometric correction of the other image was done from image to image registration strategy with refer to 1975 image. The former acquired image of the study area was geometrically corrected using 
32 control points and its RMSE was estimated about 0.49 pixels. Satellite image interpretation is based primarily on Landsat MSS and TM data acquired on 1975 and 2001, at 80 and $30 \mathrm{~m}$ spatial resolution in the multispectral bands and $120 \mathrm{~m}$ spatial resolution in band of 6 of TM. Neither scene was hampered by the presence of cloud cover and both were georeferenced to UTM Zone (WGS84). For the training area and accuracy assessment of the land cover a numbers of reference datasets were constructed on the used images. Reference data for the 2001 Landsat ETM+ and 1975 Landsat MSS imagery were obtained from the topographic maps of the study area (at the scale of 1:50,000) which have published by the Iranian NCC in 2002 and land cover map of 1976, respectively. The topographic maps were compiled from aerial photographs and subsequent ground truthing. Thus a ground truth map was prepared to locate the training pixels on the images. Additionally, 110 reference points were recorded using GPS and then transferred to GIS environment for the accuracy evaluation of the derived land cover of 2001.

Image enhancement and visual interpretation The purpose of image enhancement is to improve the visual interpretability of an image by increasing the apparent distinction between the features. The process of visually interpreting digitally enhanced imagery attempts to optimize the complementary abilities of the human mind and the computer. The mind is excellent at interpreting spatial attributes on an image and is capable of identifying obscure or subtle features (Lillesand and Kiefer, 1994). Contrast stretching was applied on the two images and two false color composites (FCC) were produced. These FCC were visually interpreted using on screen digitizing in order to delineate land cover classes that could be easily interpreted such as built-up area, forest and agricultural land. Some classes were spectrally confused and could not be separated well by supervised classification and hence visual interpretation was required to separate them.

\section{RESULTS AND DISCUSSIONS}

Land cover classes are typically mapped from digital remotely sensed data through the process of a supervised digital image classification. The overall objective of the image classification procedure is to automatically categorize all pixels in an image into land cover classes or themes (Lillesand and Kiefer, 1994). The maximum likelihood classifier quantitatively evaluates both the variance and covariance of the category spectral response patterns when classifying an unknown pixel so that it is considered to be one of the most accurate classifier since it is based on statistical parameters. Supervised classification was done using ground checkpoints, land cover map and digital topographic maps of the study area. The area was classified into three main classes of forest, built-up area and agricultural land. Description of theses land cover classes are presented in Table 1 . Then accuracy assessment was carried out using 200 points (polygon for classification), 150 point from field data in 2009 and 50 points of land cover map of 1976 . The location of the used 200 points was selected through a random stratified method to represent different land cover classes of the area. In order to the increase of an accuracy of land cover mapping of the two images, supplementary data and the result of visual interpretation was integrated with the classification result using GIS in order to improve the classification accuracy of the classified image. A supervised classification of images was approved using the maximum likelihood method. This decision rule is based on the probability that a pixel belongs to a particular class with the highest probability among of several possibilities. The algorithm is more computation intensive and therefore slower than most of the other classification algorithms, but the accuracy of classification is usually higher, especially in cultural, small-area heterogeneous landscapes (Huss, 1984).

All the satellite data were thoroughly studied using spectral and spatial profiles to ascertain the digital numbers (DNs) of different land cover types prior to classification. Training samples were selected through reference data and ancillary information which have mentioned earlier. A supervised maximum likelihood classification (MLC) algorithm was subsequently applied to each image which has generally proven to obtain the best results from remotely-sensed data if each class has a Gaussian distribution (Bolstad and Lillesand 1991). Postclassification refinement therefore was used to improve the accuracy as it is simple, efficient and easily executable method (Harris and Ventura 1995). A $3 \times 3$ majority filter finally applied to the classified land cover data to reduce the salt-and pepper effect according to Lillesand and Kiefer,s recommendation in 1999 (Fig.2). To determine the changes in land use/cover at different time, a post classification comparison of change detection was used. Even though this technique presents few limitations (Singh 1989; Coppin et al. 2004), it is the most common approach (Jensen 1996; Mundia and Aniya 2006) to compare data from different sources and dates. The 
advantage of post classification comparison is that it by passes the difficulties associated with the analysis of images acquired at different times of the year and/or by different sensors (Yuan et al. 2005; Coppin et al. 2004; Alphan 2003). Moreover, the post classification method also answers the amount, location, and nature of change (Howarth and Wickware 1981)

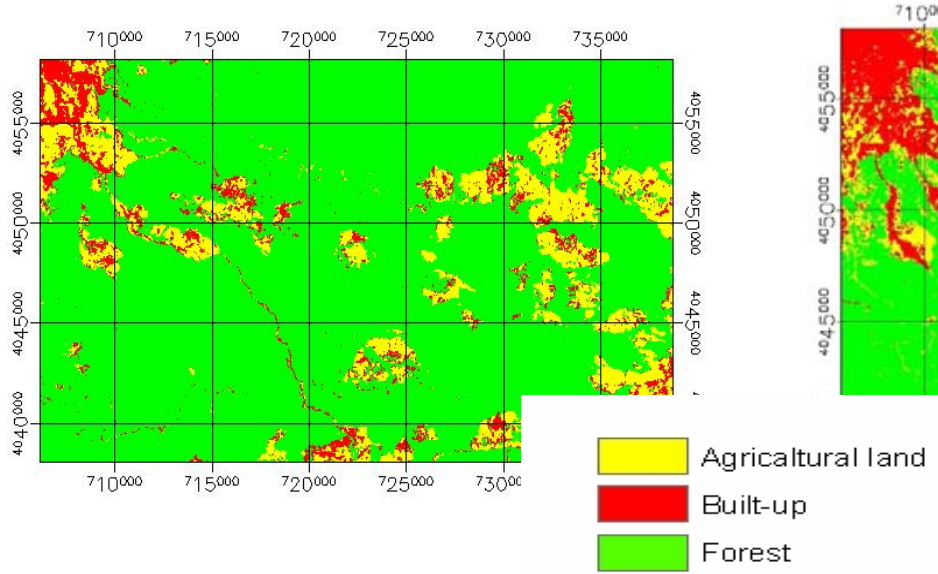

1975

Fig. 2 Land use/ cover of study area

2001

cover classes defined in table 1 as the main classes. An equalized stratified random sampling approach was used to assess the accuracy of each of the three cover classifications. The Overall accuracy, Producer's, User's, Commission, Omission and a KAPPA analysis were used to perform classification accuracy assessment based on error matrix analysis.

Table 1: Land use/cover characteristics of Neka basin

\begin{tabular}{|ll|}
\hline $\begin{array}{l}\text { Land } \\
\text { use/cover }\end{array}$ & \multicolumn{1}{c|}{ Descriptions } \\
\hline Forest & $\begin{array}{l}\text { Areas covered by dense forest with } \\
\text { relatively darker green colures, deciduous } \\
\text { forest, mixed forest lands, scrub and others }\end{array}$ \\
\hline $\begin{array}{l}\text { Agricultural } \\
\text { land }\end{array}$ & $\begin{array}{l}\text { Cropland, Pasture and Other agricultural } \\
\text { land }\end{array}$ \\
\hline Built -up & $\begin{array}{l}\text { Residential, commercial and services, } \\
\text { industrial, transportation, roads, mixed } \\
\text { urban, and other urban }\end{array}$ \\
\hline
\end{tabular}

Using the simple descriptive statistics technique, overall accuracy is computed by dividing the total correct by the total number of pixels in the error matrix. KAPPA analysis is a discrete multivariate technique used in accuracy assessments (Jensen 1996). KAPPA analysis yields a Khat statistic (an estimate of KAPPA) that is a measure of agreement or accuracy (Congalton 1991). The Khat statistic is 
computed as:

$$
K_{\text {hat }}=\frac{N \sum_{i=1}^{r} x_{i i}-\sum_{i=1}^{r}\left(x_{i+} x_{+} i\right)}{N^{2}-\sum_{i=1}^{r}\left(x_{i+} x_{+} i\right)}
$$

Where $r$ is the number of rows in the matrix, Xii is the number of observations in row $\mathrm{i}$ and column $\mathrm{i}, \mathrm{Xi}+$ and $X+i$ are the marginal totals for row $i$ and column $i$ respectively and $\mathrm{N}$ is the total number of pixels. Table 2 shows overall classification accuracy and kappa results of the study area.

Finally, accuracy reports of each land cover data in terms of overall accuracy, producers/users accuracy, and kappa coefficient have been generated.

Table 2 Results of classification accuracy

\begin{tabular}{ccc}
\hline Images & Overall accuracy (\%) & Kappa(\%) \\
\hline 1975 Landsat MSS & 99.44 & 97.08 \\
2001 Landsat ETM $^{+}$ & 85 & 83 \\
\hline
\end{tabular}

Table 3 Summary of land use/cover classification statistics between 1987 and 2001 (area in km²)

\begin{tabular}{llcccc}
\hline \multirow{2}{*}{ Land use/cover types } & \multicolumn{2}{c}{1975} & & 2001 \\
& & & & \\
\cline { 2 - 5 } & Area & $(\%)$ & Area & $(\%)$ \\
& & & & & \\
\hline Forest & 547.4981 & 83.60 & 479.5808 & 73.31 \\
Built-up & 34.3080 & 5.23 & 41.6676 & 6.370 \\
Agricultural land & 73.0512 & 11.15 & 132.9182 & 20.31 \\
& & & & & \\
\hline
\end{tabular}

Table4 Summary of classification accuracies (\%) for 1987, 2001.

\begin{tabular}{|l|c|c|c|c|c|c|c|c|}
\hline \multirow{2}{*}{$\begin{array}{l}\text { Land } \\
\text { use/cover } \\
\text { types }\end{array}$} & \multicolumn{9}{|c|}{1975} & \multicolumn{3}{|c|}{2001} \\
\cline { 2 - 8 } & Producer's & User's & Commission & Omission & Producer's & User's & Commission & Omission \\
\hline Forest & 99.49 & 99.99 & 0.01 & 0.51 & 98.84 & 99.87 & 0.13 & 1.16 \\
Built up & 92.71 & 43.41 & 56.59 & 7.29 & 81.68 & 55.72 & 44.28 & 18.32 \\
Agricultural & 97.45 & 85.22 & 14.78 & 2.55 & 79.12 & 80 & 20 & 20.88 \\
land & & & & & & & & \\
\hline
\end{tabular}

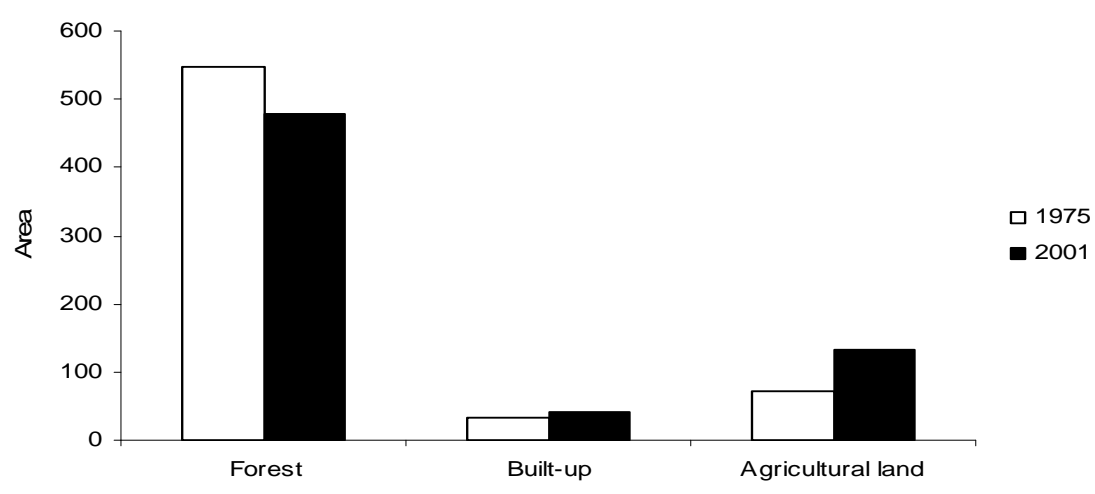

Fig. 3 Land use/cover Area $\left(\mathrm{km}^{2}\right)$ within Neka River throughout the study period (1975-2001). 
Agric. Biol. J. N. Am., 2010, 1(6): 1148-1157

Table 5. Cross-tabulation of land use/covers classes between 1975 and 2001 (area in km$^{2}$ )

\begin{tabular}{ccccccc}
\hline & & \multicolumn{2}{c}{1975} \\
\cline { 3 - 7 } & & & Forest & Agricultural land & built-up & Total \\
\hline \multirow{3}{*}{2001} & Forest & 447.44 & 5.84 & 11.99 & 465.27 \\
\cline { 2 - 7 } & Agricultural land & 24.88 & 10.42 & 14.77 & 49.47 & 139.14 \\
\cline { 2 - 7 } & built-up & 74.38 & 18.02 & 46.74 & 653.88 \\
\hline
\end{tabular}

Land-use and -cover change (LULC) are among the most important alterations of the Earth's land surface (Lambin et al., 2001). Consequently, understanding and predicting the causes, processes and consequences of LUCC has become a major challenge to anyone involved in landscape ecology, regional land-use (LU) planning. Post classification comparison can be effective method when it has to express the specific nature of changes compiled with statistics in terms of tables, graphs or change maps. In this study both images of 1975 and 2001were classified successfully which are comparable and could easily identify the areas where the changes have occurred related to the maps as well as from graph (Fig. 3).

The visual interpretation gave a general idea about the forms of land cover changes over the period. The nature of land cover changes revealed that the builtup and agricultural land categories have been increased significantly (Table 3). For instance, in 1975 agricultural land areas were $73.05 \mathrm{~km}^{2}$ $(11.15 \%)$ which increased gradually to $132.91 \mathrm{~km}^{2}$ (20.319\%) in 2001 which indicates that $10 \%$ growth within 25 years interval and also built-up areas increased to $1 \%$. Table 3 is representing that between 1975 and 2001, agricultural land areas increased approximately $59.86 \mathrm{~km}^{2}$ while forest area had a declination of $67.91 \mathrm{~km}^{2}$. Figure 3 shows the area of land use/cover change during 1975-2001. Assessment of the classification accuracy of the derived land use/cover maps from satellite data was carried out. Error matrices were used to assess the classification accuracy and are summarized for 2 years in Table 1, 4. The overall accuracies for 1975, 2001 were $99.44 \%$ and $97.08 \%$ respectively, with Kappa statistics of $85 \%$ and $83 \%$. Producer's and user's accuracy was also consistently high, ranging from $43 \%$ to $100 \%$ and Commission and Omission was derided that from $0.01 \%$ to $60 \%$ (Table 4). Errors of commission represent pixels that belong to the other class that are labeled as belonging to the class of interest. The errors of commission are shown in the rows of the confusion matrix. The ratio of the number of pixels classified incorrectly by the total number of pixels in the ground truth class forms an error of commission. Errors of omission represent pixels that belong to the ground truth class but the classification technique has failed to classify them into the proper class. The errors of omission are shown in the columns of the confusion matrix. The ratio of the number of pixels classified incorrectly by the total number of pixels in the ground truth class forms an error of omission (Bradley, 1997). Remote sensing data provide opportunities for integrated analysis of spatial data. Cross-tabulation performs image cross-tabulation in which the categories of one image are compared with those of a second image and tabulation is kept of the number of cells in each combination.

\section{CONCLUSIONS}

For general research studies of land cover/land use or their change analysis, satellite data of high spatial resolution or different spectral properties and various remote-sensing technologies are importance. In this study, land use/cover changes in Neka River were analyzed, benefiting mainly from the spectral properties of multi-temporal satellite data. Using a post-classification comparison, the dynamics of land use/cover change are presented. Furthermore, monitoring of built-up areas, land use changes, unplanned or informal structure, will greatly benefit from high-resolution satellite data.

Urban growth was mainly driven by population migration interested in this area. Also, a decline or total loss of forest area in various section of the area due to the rapid increase of deforestation has been determined. Overall, the long-term change detection analysis in this study showed that the land in the last decade significantly changed the land cover patterns in this region so much that the land management, ecological conservation, and control actions have become a new challenge to the environmental decision makers in this area. This study was provided detailed analyses and monitoring of the land use/cover changes over time by applying modem technique of remote sensing; forming an 
important step towards warning the related authorities on the consequences of the land use/cover changes. Such studies aim to inform the managers, decision-makers and urban planners of the past and current land cover changes, and to influence the illegal urbanization through appropriate urban management, environmental policy. The scientists and engineers of different disciplines must come together to put force the actual situation both visually and analytically to alert the practitioners that have the right to take necessary precautions and measures against further deterioration of the environment. There is an increasing need for the use of science based decisions for policy making in Neka-rude. Information on land use/cover change is thus critically important. Natural resource managers in particular have recognized the value of this type of information for resource management and sustainable development.

Agricultural land areas increased significantly from $11.15 \%$ to $20.31 \%$ which is mainly attributed to the fast increase of deforestation due to large area. Consequently, forest areas are reducing rapidly.

The accuracy of the maps was satisfactory, the highest accuracy obtained for the Landsat MSS data while the lowest accuracy attained for the ETM+ image. The study took the advantage remote sensing techniques to quantify the land use/cover change in Neka River over the last 25years. Due to the deficiency of land use/cover maps of the study area and restricted access to aerial photographs/ geospatial database, satellite data can be operationally used to generate land use/cover dynamics, and are useful for Neka and elsewhere for sustainable land management and policy makings. In order to increase the accuracy of land cover mapping of the two images, ancillary data and the result of visual interpretation was integrated with the classification results using GIS. A standard overall accuracy for land-cover and land-use maps is set between 85 (Anderson, Hardy, Roach, and Witmer, 1976) and 90 percent (Lins and Kleckner, 1996). In this study the overall classification accuracy was estimated to 99.44 percent for 1975 and 97.08 percent for 2001. Details of single class accuracy for both images of 1987 and 2001 can also be found in Table 4.

\section{ACKNOWLEDGEMENTS}

This work was funded by the Faculty of Natural Resources of Sari-Iran, M.Sc Proposal (M. Arekhi). The authors would like to thank GIS and RS Centre of the University of Agric. and Natural Res., Sari, Iran for technical and financial supports.

\section{REFERENCES}

Adams, J.B., Sabol, D.E., Kapos, V., Almeida-Filho, R., Roberts, D.A., Smith, M.O. and Gillespie, A.R. (1995). Classification of multispectral images based on fractions of endmembers: application to land-cover change in the Brazilian Amazon. J. Remote Sensing Environ, 52:137-154

Alphan, H. (2003). Land use change and urbanization in Adana, Turkey. Land Degradation and Development, 14 (6):575-586

Asner, G.P., Knapp, D.E., Broadbent, E.N., Oliveira, P. J.C, Keller,M., Silva, J.N., (2005). Selective logging in the Brazilian Amazon. Science, 21, Vol. 310, No. 5747:480-482

B1odget, H., Taylor, P. and Roark, J., (1991). Shoreline changes along the Rosetta-Nile Promontory: monitoring with satellite observations. Marine Geology 99:67-77

Bolstad, P.V. and Lillesand, T.D., (1991). Rapid Maximum Likelihood classification. J. Photogrammetric Engineering and Remote Sensing 57:67-74

Bradley, A.P. (1997). The use of the area under the ROC Curve in the evaluation of machine learning algorithms. Pattern Recognition, 30(7):1145-1159

Chan, J.C.; Chan, K.P. and Yeh, A.G.O. (2001). Detecting the nature of change in an urban environment: $A$ comparison of machine learning algorithms. Photogrammetric Engineering and Remote Sensing 67(2), 213-225.

Chavez, P.S. (1996). Image-based atmospheric corrections-revisited and improved. Photogrammetric Engineering and Remote Sensing 62(9):1025-1036

Chowdhury, A.M. and Faruqui, S., (1989). Physical growth of Dhaka City. In S.u. Ahmed (Ed) Dhaka: past, present and future. Dhaka: The Asiatic Society of Bangladesh. 3-61

Cihlar, I. and Jansen, L.J. M., (2001). From land cover to land use: A methodology for efficient land use mapping over large areas. Professional Geographer 53(2), 275289

Congalton, R.G., (1991). A review of assessing the accuracy of classifications of remotely sensed data. J. Remote Sensing of Environ. 37, 35-46

Coppin, P., Jonckheere, I., Nackaerts, K., Muys, B. and Lambin, E. (2004). Digital change detection methods in ecosystem monitoring: a review. International J. Remote Sensing 25(9):1565-1596

Di Gregorio, A. and jansen, L.J.M., (2000). Land-cover classification system (LCCS): Classification concepts 
and user manual. Cooperazione Italiana, Rome. pp 179

Ehlers, M., Jadkowski, A.M., Howard, R. and Brostuen, D. (1990). Application of spot data for regional growth analysis and local planning. Photogrammetric Engineering and Remote Sensing 56(2):175-180

Foody, G.M. (2002). Status of land cover classification accuracy assessment. J Remote Sensing of Environ. 80(1):185-201

Foody, G.M. and Boyd, D.S. (1999). Detection of partial land cover change associated with the migration of inner-class transitional zones. International J. Remote Sensing 20(14):2723-2740

Giri, C., Zhu, Z. and Reed, B. (2005). A comparative analysis of the Global Land Cover 2000 and MODIS land cover data sets. J. Remote Sensing of Environ. 94(1):123-132

Green, G.M., Schweik, C, and Hanson, M. (2002). Radiometric calibration of LANDSAT multi-spectral scanner and thematic mapper images: Guidelines for the global change community. Bloomington: Center for the Study of Institutions, Population, and Environmental Change (CIPEC), Indiana University. CWP-02-03

Harris, P.M. and Ventura, S.J. (1995). The integration of geographic data with remotely sensed imagery to improve classification in an urban area. Photogrammetric Engineering and Remote Sensing 61(8), 993-998.

Hathout, S., (2002). The use of GIS for monitoring and predicting urban growth in East and West St Paul, Winnipeg, Manitoba, Canada. J Environmental Management 66(3):229-238

Helmschrot, J., Flugel, W.A., (2002). Land use characterisation and change detection analysis for hydrological model parameterisation of large scale afforested areas using remote sensing. Physics and Chemistry of the Earth 27(9-10):711-718

Herold, M., Goldstein, N.C. and Clarke, K.C. (2003). The spatiotemporal form of urban growth: measurement, analysis and modeling. J. Remote Sensing of Environ, 86:286-302

Hill, R.A., (1999). Image segmentation for humid tropical forest classification in Landsat TM data. International J. Remote Sensing of Environ. 20(5):1039-1044

Howarth, P.J. and Wickware, G.M. (1981). Procedures for change detection using Landsat digital data. Int. J. Remote Sensing Environ. 2(3):277-291

Irish, R., (1990). Geocoding satellite imagery for GIS use. GIS World, August/September, 59-62

Islam, N., (1996). Dhaka: from city to megacity: perspectives on people, places, planning and development issues/Nazrul Islam. Dhaka: Urban Studies Program, Bangladesh urban studies series; no. 1,242

Jansen, LJ.M., (2005). Harmonisation of LU class sets to facilitate compatibility and comparability of data across space and time. J. Land Use Sci. 1(2):127-56

Jensen, I.R., Ramsey, E., Mackey, H.J.R., Christensen, E. and Sharitz, R. (1987). Inland wetland change detection using Aircraft MSS data. Photogrammetric Engineering and Remote Sensing 53(5):521-529

Jensen, J.R., (1996). Introductory digital image processing. New Jersey, USA: Prentice Hall, 401

Jensen, J.R. and Kalmesh, I., (1987. Introductory digital image processing: a remote sensing perspective. Geocarto International 2(1):65

Khorram, S., Biging, G.S., Chrisman, N.R., Congalton, R.G., Dobson, J.E. and Ferguson, R.L. (1999). Accuracy assessment of remote sensing-derived change detection. Bethesda: Am. Soc. Photogrammetry and Remote Sensing.48-68

Lambin, E.E, and Geist, H.J. (2001). Global Land-cover changes-What have we learned so far? IGBP Global Change Newsletter 46:27-30

Lambin, E.E., Geist, H.J. and Lepers, E. (2003). Dynamics of land use and cover change in tropical regions. Annual Rev. Environ and Resources 28:205-241

Lambin, E.E., Turner, B.L., Geist, H., Agbola, S., Angelsen, A., Bruce, J.W., Oliver, T. C., Rodolfo, D., Gunther, F., Carl, F. and George, P.S., (2001). The causes of LU and land-cover change: Moving beyond the myths. Global Environmental Change 11(4), 261-269

Lambin, E.F., (1997). Modeling and monitoring land-cover change processes in tropical regions. Progress in Physical Geography, 21(3):375-393

Lillesand, T.M. and Kiefer, R.W. (1999). Remote Sensing and Image Interpretation. New York: John Wiley and Sons.

Lopez, E, Bocco, G., Mendoza, M. and Duhau, E., (2001). Predicting land cover and land use change in the urban fringe a case in Morelia City, Mexico. Landscape and Urban Planning 55(4):271-285

Lu, D., Mausel, P., Batistella, M. and Moran, E., (2004). Comparison of land-cover classification methods in the Brazilian Amazon Basin. Photogrammetric engineering and remote sensing 70(6):723-731

Lu, D., Mausel, P., Brondizio, E. and Moran, E., (2002). Assessment of atmospheric correction methods for landsat TM data applicable to Amazon basin LBA research. Int. J Remote Sensing 23(13):2651-2671

Lu, D., Moran, E.E. and Batistella, M., (2003). Linear mixture model applied to Amazonian vegetation 
classification. Remote sensing of environment 87:456469

Maktav, D. and Erberk, E.S., (2005). Analysis of urban growth using multi-temporal satellite data in Istanbul, Turkey. Int. J. Remote Sensing 26(4):797-810

Markham, B.L. and Barker, J.L. (1987). Radiometric properties of U.S. processed Landsat MSS data. Remote Sensing of Environ. 22:39-71

Markham, B.L. and Barker, J.L. (1985). Spectral characterization of the LANDSAT Thematic Mapper sensors. Int. J. Remote Sensing 6(5):697 -716

Muchoney, D.M. and Haack, B.N., (1994). Change detection for monitoring forest defoliation. Photogrammetric Engineering and Remote Sensing 60(10):1243-1251

Mundia, C.N., Aniya, M. (2006). Dynamics of land use/ cover changes and degradation of Nairobi City, Kenya. Land Degradation and Development, 17(1):97-108

Neckel, H., and Labs, D., (1984). The solar radiation between 3300 and 12500 A. Solar Physics, 90:205258

Ozel M.E., Ylldlnm H., Alparslan E., Aydoner C., Elita, S., Divan J., Dagcl M., Donerta, A. and Erkan B., (1999). Development of a GIS DataBase of Yeillremak Watershed Using RS and GIS, Turkish German Geodetic Days, Berlin, proceedings, Germany 2:589598

Pal, M. and Mather, P.M. (2003). An assessment of the effectiveness of decision tree methods for land cover classification. Remote Sensing of Environ. 86(4):554565

Palmer, A.R. and Van Rooyen, A.F., (1998). Detecting vegetation change in the southern Kalahari using Landsat TM data. Journal of Arid Environments 39(2), 143-153.

Ram, B., Kolarkar, and A.S. (1993). Remote sensing application in monitoring land-use changes in arid Rajasthan. J. Arid Environ. 14(17):3191-3199

Roy, D.P., Lewis, P.E. and Justice, C.O. (2002). Burned area mapping using multi-temporal moderate spatial resolution data-a bi-directional reflectance model- based expectation approach. Remote Sensing of Environment 83(1-2):263-286

Serra, P., Pons, X, and Sauri, D. (2008). Land-cover and land-use change in a Mediterranean landscape: a spatial analysis of driving forces integrating biophysical and human factors. Applied Geograph 28(3):189-209

Singh, A., (1989). Digital change detection techniques using remotely sensed data. International Journal of Remote Sensing 10(6), 989-1003.

Steele, B.M., (2000). Combining multiple classifiers: an application using spatial and remotely sensed information for land cover type mapping. Remote Sensing of Environ. 74(3):545-555

Treitz, P.M., Howarth, P.J. and Gong, P. (1992). Application of satellite and GIS technology for land-use mapping at the rural urban fringe: A case study. Photogrammetric Engineering and Remote Sensing, 58:439-448

Welch, R., Remillard, M.M. and Slack, R.B., (1988). Remote sensing and geographic information system techniques for aquatic resource evaluation. Photogrammetric Engineering and Remote Sensing 54(2):177-185

Westmoreland, S. and Stow, D.A. (1992). Category identification of change of land-use polygons in an integrated image processing/geographic information system. Photogrammetric Engineering and Remote Sensing 58(11):1593-1599

Yuan, F., Sawaya, K.E, Loeffelholz, B.C. and Bauer, M.E., (2005). Land cover classification and change analysis of the Twin Cities (Minnesota) Metropolitan Area by multitemporal Landsat remote sensing. Remote Sensing of Environ. 98(2-3):317-328

Zhang, B.P., Yao, Y.H., Cheng, W.M., Zhou, C H., Lu, Z. and Chen, X.D. (2002). Human-induced changes to biodiversity and alpine pastureland in the Bayanbulak Region of the East Tianshan Mountains. Mountain Research and Development 22(4):383-389

Zhang, Q., Wang, J., Peng, X. and Shi, P. (2002). Urban built-up change detection with road density and spectral information from multi-temporal Landsat TM data. Int. J. Remote Sensing 23(15):3057-3078 